\title{
Engineering the interface energetics of solar cells by grafting molecular properties onto semiconductors
}

\author{
DORI GAL ${ }^{\mathrm{a}}$, ELI SONE ${ }^{\mathrm{a}}, \mathrm{R}_{\text {COHEN }}^{\mathrm{a}}, \mathrm{G} \mathrm{HODES}^{\mathrm{a}}, \mathrm{J}$ LIBMAN $^{\mathrm{b}}$, \\ A SHANZER ${ }^{\mathrm{b}}, \mathrm{H}-\mathrm{W} \mathrm{SCHOCK}^{\mathrm{c}}$ and DAVID CAHEN ${ }^{2 *}$ \\ a Department of Materials \& Interfaces, Weizmann Institute of Science, Rehovot, \\ Israel, 76100 \\ ${ }^{b}$ Department of Organic Chemistry, Weizmann Institute of Science, Rehovot, \\ Israel, 76100 \\ 'Institute für Physikal, Elektronik, University of Stuttgart, Germany, 70589
}

\begin{abstract}
The electronic properties of semiconductor surfaces can be controlled by binding tailor-made ligands to them. Here we demonstrate that deposition of a conducting phase on the treated surface enables control of the performance of the resulting device. We describe the characteristics of the free surface of single crystals and of polycrystalline thin films of semiconductors that serve as absorbers in thin film polycrystalline, heterojunction solar cells, and report first data for actual cell structures obtained by chemical bath deposition of $\mathrm{CdS}$ as the window semiconductor. The trend of the characteristics observed by systematically varying the ligands suggests changes in work function rather than in band bending at the free surface, and implies that changes in band line-up, which appear to cause changes in band bending, rather than direct, ligand-induced band bending changes, dominate.
\end{abstract}

Keywords. Photovoltaics; solar cells; semiconductor surfaces; CdTe crystals; CdS deposition.

\section{Introduction}

\section{Photovoltaics}

Photovoltaics (PV) is a rapidly advancing field. Most of the presently installed photovoltaic capacity uses wafers of crystalline silicon. Silicon-based photovoltaic cells are used largely in applications that are distant from a utility grid because electricity produced with these cells remain from three to seven times more expensive than conventionally generated electrical power. Research efforts to make PV a more viable energy generating alternative are focused in two main directions, viz. the development of high efficiency solar cells and the development of much cheaper ones. High efficiency work concerns mainly cells based on the elemental semiconductor Si and on III-V compounds, including ternary and multinary alloy systems. Programs in this direction deal primarily with single crystalline bulk or thin film, and, in the case of Si also with large grain polycrystalline substrates.

Thin film solar cells

Thin-film amorphous or polycrystalline photovoltaic cells emerged in an attempt to make solar electricity less expensive. These cells absorb light in a thin film of

\footnotetext{
*For correspondence
} 
semiconductor material, and they promise reasonable efficiency at greatly decreased cost. Thin-film photovoltaic cells should be more cost-competitive than conventional silicon-wafer cells because of materials and production considerations. Indeed, work on the leading thin film candidate cells is concentrated on films that can be deposited on large-area substrates by low-cost processing techniques. Other factors also create advantages for thin-film photovoltaics. For example, the light-generated electrons and holes in a thin film are produced close to the space charge region, so there is a high probability that they will be separated rather than recombine.

Research on thin-film photovoltaics is concentrated on three types of materials, I-III-VI ${ }_{2}$-based chalcopyrites, cadmium telluride (encountering fierce environmental opposition), and amorphous silicon (sold by several manufacturers but suffering from a hitherto unsolved stability problem for high efficiency devices) [cf. refs. 1 for general overviews of the state of the art].

Probably the major problem in optimizing solar cells, and in general, electronic devices that use thin polycrystalline films, is that of finding conditions for minimal current and voltage loss across the grain surfaces and interfaces. This is easy to understand as losses of this type will scale in one way or the other with the surface and interface areas, areas that will increase with decreasing grain size. This problem can be alleviated by increasing the grain size, but this will ultimately run counter to the idea behind polycrystalline devices, which often is simplicity and keeping down the cost of their fabrication ${ }^{2}$.

Among the many promising I-III- $\mathrm{VI}_{2}$ compounds, several $\mathrm{Cu}$ ternaries, $\mathrm{CuInSe}_{2}$ $(\mathrm{CISe})^{3}, \mathrm{CuInS}_{2}(\mathrm{CIS}), \mathrm{CuGaSe}_{2}$ and their quartenary and pentenary solid solutions, $\mathrm{Cu}(\mathrm{Ga}, \mathrm{In})(\mathrm{Se}, \mathrm{S})_{2}$, have been evaluated for $\mathrm{PV}$ applications. $\mathrm{CuInSe}{ }_{2}$ and its quartenary solid solution $\mathrm{Cu}(\mathrm{Ga}, \mathrm{In}) \mathrm{Se}_{2}(\mathrm{CIGSe})$ are, by far, the most advanced $\mathrm{PV}$ materials in their class. The interest in CISe as a photovoltaic material was stimulated by the demonstration of a $12 \%$ efficient CdS/CISe solar cell on a single crystal wafer of this material in $1975^{4}$. Soon after, thin-film solar cells were demonstrated ${ }^{5}$. Since then this heterojunction design has been used successfully in polycrystalline thin film CISe devices ${ }^{6-8}$. Recently, high efficiencies exceeding $15 \%$ have been achieved by a number of groups, including the IPE-Stuttgart one ${ }^{9}$. In the case of higher band gap materials, results are lagging and best results for cells based on $\mathrm{CuInS}_{2}$-based films are around $12 \%{ }^{10}$ and for $\mathrm{CuGaSe}_{2}$ films (crystals) $6-7 \%{ }^{11}(9 \cdot 7 \%)^{12}$ only, notwithstanding their apparently favorable band gaps of 1.56 and $1.67 \mathrm{eV}$. In addition to low-Ga $\mathrm{Cu}(\mathrm{In}, \mathrm{Ga}) \mathrm{Se}_{2}$ alloys, also high-Ga ones as well as $\mathrm{CuIn}(\mathrm{S}, \mathrm{Se})_{2}$ films have been used as absorbers, to increase the open circuit voltage of cells, but with increasing band gap, considerable efficiency decreases are observed. Generally speaking this is attributed to lower than expected open-circuit voltage, which in turn may be caused by shunt conductance ${ }^{13}$.

\section{Windows for heterojunction cells}

The cell is formed by depositing a film of another semiconductor on the absorbing film. In the case of the CISe-based solar cells the term "window" has been used to denote both this semiconductor layer-sometimes referred to as the buffer layer (CdS in most cases) and the conducting oxide contact (usually $\mathrm{ZnO}$ ). Here we use window in the former sense. Several materials have been considered for the n-type window layer on CISe based heterojunctions, including CdS, $(\mathrm{Cd}, \mathrm{Zn}) \mathrm{S}, \mathrm{ZnSe}, \operatorname{In}(\mathrm{OH})_{3}, \operatorname{In}_{x}(\mathrm{OH}, \mathrm{S})_{y}$, 
$\mathrm{Sn}(\mathrm{O}, \mathrm{S})_{2}$ and $\mathrm{ZnO}$. Only sulfides, $\mathrm{In}(\mathrm{OH})_{3}, \mathrm{ZnSe}, \operatorname{In}_{x}(\mathrm{OH}, \mathrm{S})_{y}$ and $\mathrm{Sn}(\mathrm{O}, \mathrm{S})_{2}{ }^{14.15}$ have been successfully used to fabricate high-efficiency cells. Consistently, no window material has been able to match chemical bath deposited (CBD) CdS in terms of cell performance.

The material of the window layer is an important parameter that affects the performance of solar cells. The main demand from this layer is a wide energy gap, $\mathrm{E}_{\boldsymbol{g}}$, to transmit most of the visible and near infrared part of the radiation to the absorber where carriers are generated. However, a thick window layer film does absorb a significant part of the spectrum in the blue region, and this results in a loss of photocurrent and efficiency. To minimize this undesirable absorptive loss, the window layer should be thin, yet continuous and coherent. This is especially important for polycrystalline absorber solar cells because of their inherent surface roughness.

\section{$C d S$}

$\mathrm{CdS}$, a direct gap semiconductor with an $\mathrm{E}_{g}=2.4 \mathrm{eV}$ at room temperature, transmits most of the visible and near-infrared part of the radiation to the absorber where carriers are generated. To minimize absorption of blue photons, the $\mathrm{CdS}$ thickness is limited to below $100 \mathrm{~nm}$, preferably around $50 \mathrm{~nm}$ in the final form. Several techniques, including vacuum evaporation, chemical vapor deposition, electrodeposition or precipitation from aqueous solutions have been used for the deposition of CdS films.

\section{Chemical bath deposition}

The deposition of CdS films from aqueous solution is a cost-effective, and easily controlled process for heterojunction formation. The solution growth method yields thin layers that exhibit perfect stoichiometry and better transmission than those produced by most other methods. The solution growth process is based on the reaction of a cadmium salt, a complex agent, and a sulfur compound in an aqueous solution. Ammonia, potassium cyanide, or triethanolamine are used as complexing agent. The amount of the complexing agent determines the free $\mathrm{Cd}$ ion concentration in the solution and hence, the growth rate of $\mathrm{CdS}$. The growth variables include reactant concentrations, $p \mathrm{H}$, and temperature. Useful films, obtained from such baths are typically $\leqslant 100 \mathrm{~nm}$ thick, smooth, specularly reflecting and coherent.

Lincot et al $^{16}$ showed that CBD is not limited to the abrupt deposition of a CdS layer on CISe, but involves chemical modifications at the interface. This includes removal of superficial oxides, elimination of $\mathrm{Cu}_{x} \mathrm{Se}$ phases which are highly conducting and have a shunting effect, and formation of a graded interface structure which could give a better lattice match by introduction of an intermediate phase between CISe and CdS, leading to a decrease of the surface recombination. These modifications are specific to the CBD process, and are a direct consequence of the use of reactions in solution. They allow material exchange (mainly ionic) at or near room temperature, by solution chemistry, which are not possible in the case of reactions in the vapor phase in vapor deposition, because of too small diffusion coefficients ${ }^{17}$.

It has thus become clear that the wet chemical methods have two effects, namely to deposit a wide band gap window layer onto an absorber and to modify the absorber surface, something that affects the energetics of the resulting interface. 


\section{Interface modification}

Interface optimization has long been an active area of research with considerable successes in the case of the leading thin film solar cells. Thus we could show several years ago that the hitherto mysterious affect of air annealing on $\mathrm{CuInSe}_{2}$-based cells can be ascribed, first and foremost to a rather simple defect chemical reaction involving Se vacancies ${ }^{18}$. This explanation was found to be of general validity for most chalcogenide semiconductors ${ }^{19}$. According to it, reaction with molecular oxygen decreases the free electron concentration in the bulk of the grains, passivates positively charged surface defects, potential electron traps and recombination centres and probably provides the first layer for a rather stable oxide layer in the case of $\mathrm{CuInSe}_{2}$. A surface treatment which has been long used for ternary chalcopyrite-based cells is rinsing the absorber layer in aqueous cyanide solution ${ }^{20}$ which removes excess copper in the form of copper chalcogenides ${ }^{21}$. These copper chalcogenides are usually degenerate semiconductors and their presence would tend to short out the interface.

In further work, using electrochemical methods, we could show that the surface of $\mathrm{CuInSe}_{2}$ is extremely responsive to the redox conditions of the contacting electrolyte showing continuous shifts of over $1 \mathrm{~V}$ in the flat band potential, i.e. in the band edge positions $^{22}$.

This then suggested the use of modified chemical oxidants to be able to fine-tune the position of the flatband potential. As a result, we embarked on a program to explore the use of tailor-made molecular ligands, that would bind chemically to the semiconductor surface and have an additional functional group that serves to tune the shift in band edge position, i.e. in electron affinity ${ }^{23}$. Choice of ligands was dictated by a number of requirements, viz. chemical binding to the semiconductor surface (i.e. chemisorption, rather than physisorption); ability to attach additonal groups to impart desired functionalities, that can be varied (to allow observation of trends) and ability to withstand conditions necessary for deposition of the subsequent layers.

In the case of $\mathrm{CuInSe}_{2}$ and related materials, we looked for groups that can bind to In in an oxide environment, because of the known In-oxide nature of this surface. In addition, this bond had to be resistant to rupture in the reducing environment used for the chemical bath deposition of the CdS window onto the absorber in this cell.

\section{Experimental}

Thin polycrystalline films of $\mathrm{Cu}(\mathrm{In}, \mathrm{Ga}) \mathrm{Se}_{2}$ (CIGSe) were prepared by four-source physical evaporation as described elsewhere ${ }^{9}$. Single crystals of CdTe were obtained from II-VI or Harrick Companies (USA). Substituted diphenyl dicarboxylic acids (cf. figure 2, inset) were used as ligands. Ligand synthesis will be described elsewhere [Moav et al to be published]. Adsorption was carried out by immersing the samples in $2.5 \mathrm{mM}$ solutions of the ligands in anhydrous acetonitrile for $24 \mathrm{~h}$. The mode of ligand binding to semiconductor surfaces was elucidated using FTIR spectroscopy, in the attenuated total reflection, transmission or grazing angle incidence reflection modes, as described earlier ${ }^{23,24}$. The effects of ligand binding to the free surface was followed by Contact Potential Difference (CPD) measurements, using the Kelvin probe technique, to obtain work function, electron affinity and band bending changes with respect to untreated surfaces ${ }^{23,24}$. CdS window layers were deposited using chemical bath deposition from a standard ammonia $(1 \mathrm{M})$ /thiourea bath. The substituted phenyl 


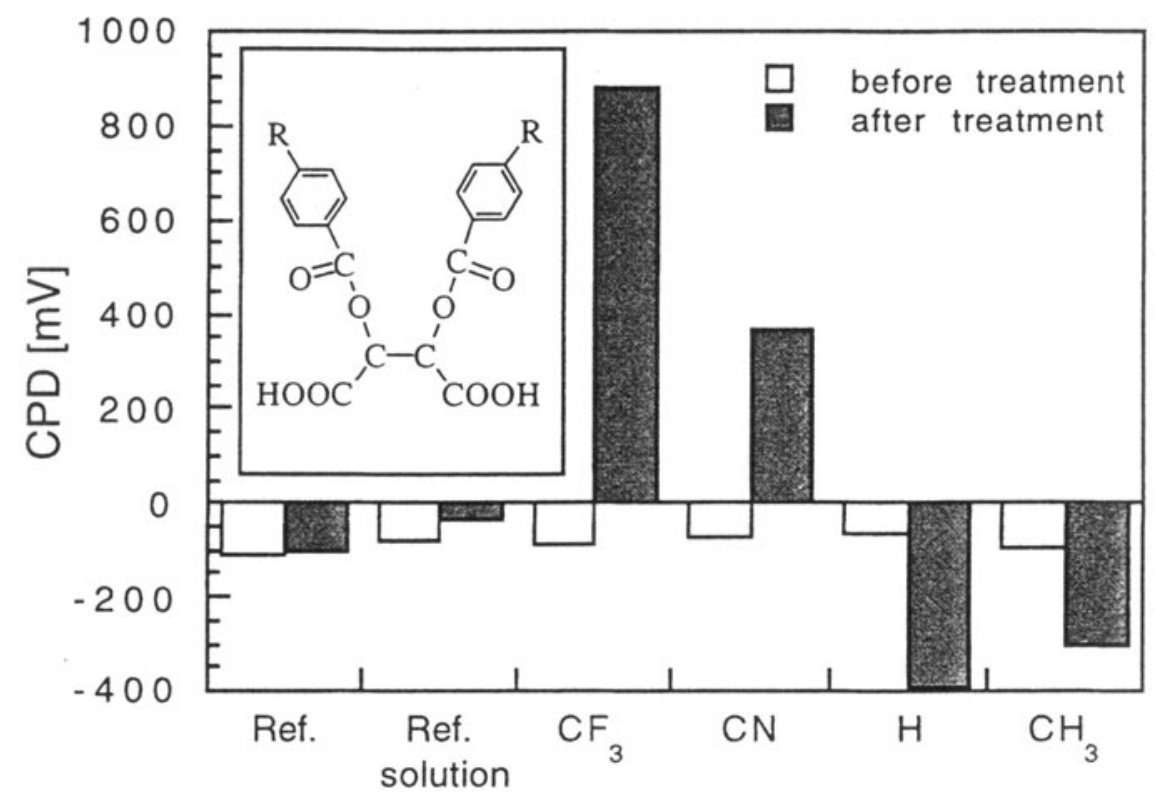

Substituent

Figure 2. Change in work function, measured as contact potential difference with a vibrating capacitor, for $\mathrm{Cu}(\mathrm{In}, \mathrm{Ga}) \mathrm{Se}_{2}$ polycrystalline thin films, after exposure to a series of ligands (cf. insert; $\mathrm{R}=\mathrm{CF}_{3}, \mathrm{CN}, \mathrm{H}, \mathrm{CH}_{3}$, Ref. -no treatment, Ref. solutiontreatment in $\mathrm{CH}_{3} \mathrm{CN}$, the solvent from which the ligands are adsorbed.)

part of the ligand is connected to the binding group via an esteric bond. Because this bond may hydrolyze in a basic environment (ammonia solution, used for the CdS deposition), the stability of the compounds in the CdS deposition solution was examined by thin layer chromatography (TLC) in $30 \mathrm{sec}$ intervals up to $2 \mathrm{~min}$. No appreciable amount of hydrolysis was observed in this time. Semi-transparent $\mathrm{Au}$ contacts, $15 \mathrm{~nm}$ thick, were deposited by vacuum evaporation. Electrical measurements were made using an HP 4155 semiconductor parameter analyzer. CPD measurements were made using a Kelvin probe arrangement (Delta-Phi Electronik, Germany). The measurements were carried out in air in the dark at room temperature. Measurements under illumination were taken using an ELH lamp.

\section{Results and discussion}

In our earlier work we showed that benzoic acids on $\mathrm{CuInSe}_{2}$ (and CdTe [24], $\mathrm{CdSe}^{25}$ and $\mathrm{GaAs}$ [to be published]), change the electron affinity of the semiconductor in a manner that roughly scales with the dipole moment of the substituted benzene ring part of the molecule. With the partial exception of $\mathrm{GaAs}$, binding those ligands to the semiconductor surface did not affect their band bending at the free surface. Therefore we looked for ligands that might have stronger effects, both in terms of binding and electrically. In particular we were interested in ligands that, upon binding, might induce some electron transfer between the surface cum adsorbed ligand and the semiconductor's space charge layer. Based on these considerations, we chose dicarboxylic acids 


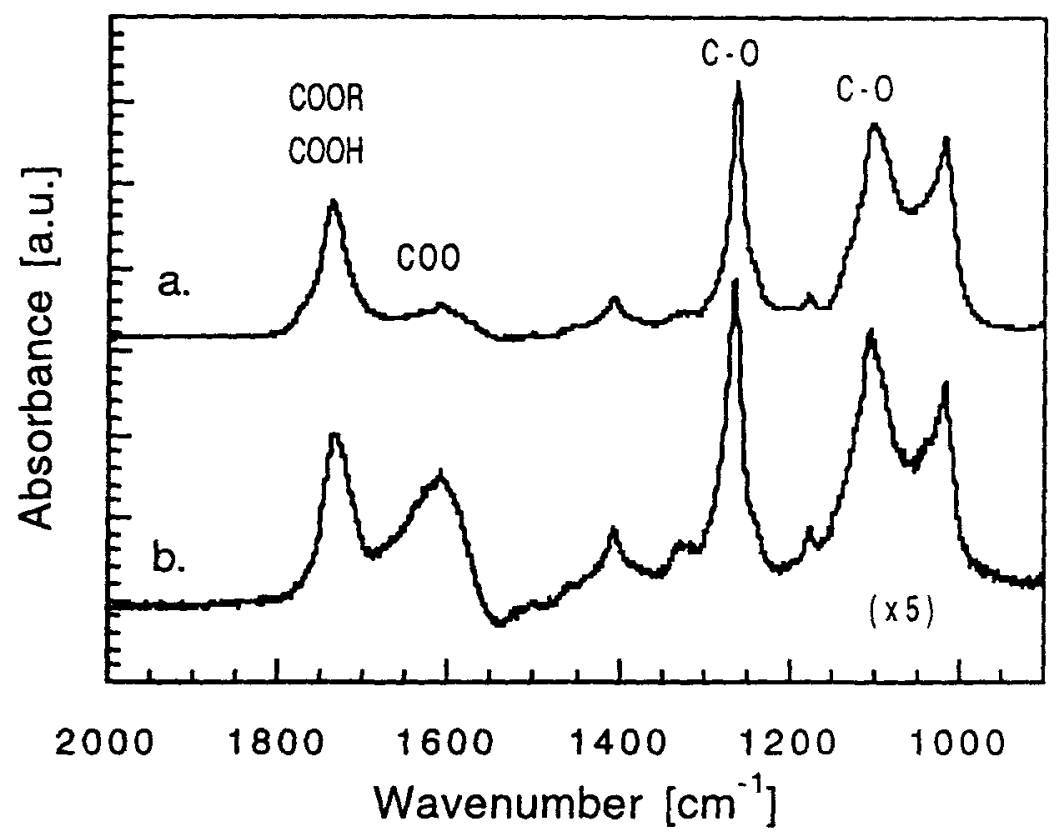

Figure 1. FTIR spectra of dicyanobenzene dicarboxylic acid on an ATR CdTe crystal. Spectrum a was taken after ligand adsorption while spectrum $b$ ( 5 times the sensitivity of spectrum a) was after rinsing with a dilute ligand solution $(0.5 \mathrm{mM})$ followed by rinsing with $\mathrm{CH}_{3} \mathrm{CN}$.

(figure 2, insert) and cyclic disulfides as surface binding groups, and substituted these compounds with a series of benzoic acid derivatives through ester linkages. The effects of the disulfides will be reported elsewhere (Bruening et al submitted for publication; cf. also $\left.{ }^{26}\right)$. Here we concentrate on the effects of the dicarboxylic acid derivatives.

We could not obtain direct evidence for chemical binding to the chalcopyrite semiconductors because neither ATR substrates, nor IR-transmitting crystals of these materials were available. We deduced binding from measurements on CdTe; such an approach is justified based on the similar behavior of CdTe and CISe in adsorbing carboxylic acids ${ }^{24}$.

Figure 1 shows FTIR spectra of the nitrile-substituted ligand on CdTe. The peak at $1735 \mathrm{~cm}^{-1}$ corresponds to the carbonyl groups, both the ester and the free acid. Of particular importance is the presence of a peak at $1620 \mathrm{~cm}^{-1}$ which corresponds to the carboxylate asymmetric stretch, showing that the ligand binds to the CdTe.

The reduction in the intensity of the former peak after rinsing off excess ligand, together with the lack of change in the bound carboxylate peak (the spectrum after rinsing is shown at five times the sensitivity of that before rinsing) supports ligand binding to the CdTe surface.

CPD measurements on CdTe crystals showed changes in work function (up to $400 \mathrm{mV}$ for the CdTe crystals). The change was largest for nitrile (CN-) substituted ligands and smallest for methoxy $\left(\mathrm{OCH}_{3}^{-}\right)$substituted ones, i.e. similar to what was observed earlier with the simpler ligands. In this case, however, in contrast 


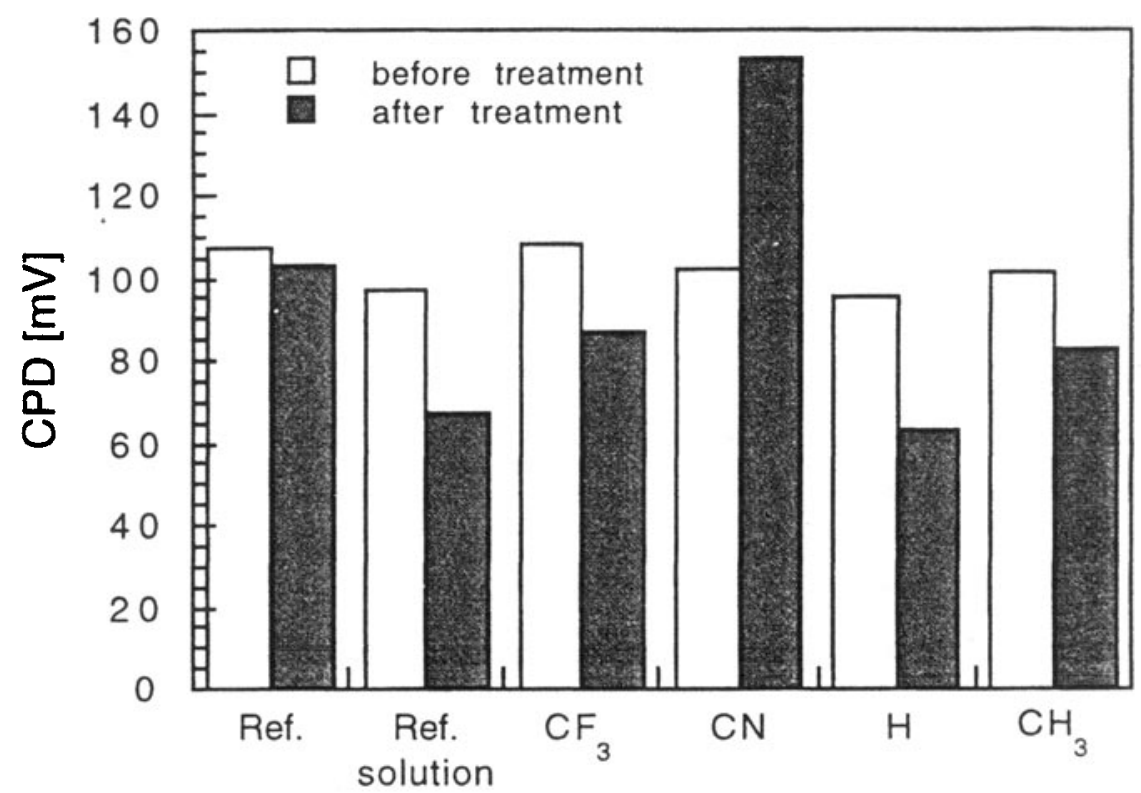

\section{Substituent}

Figure 3. Change in band bending, measured as the difference between contact potential difference measurements in the dark and under saturating illumination, for the samples of figure 3 .

to earlier work ${ }^{23-25}$, part of those changes was due to changes in band bending. If the semiconductor surface was treated with the solvent only, $600 \mathrm{mV}$ band bending was found. Exposure to CN-substituted ligands changed this to $230 \mathrm{mV}$, while exposure to methoxy $\left(\mathrm{OCH}_{3}\right)$-substituted ligands changed the band bending to $460 \mathrm{mV}$. We explain this tentatively using a simple molecular orbital picture, involving the HOMO of the ligand and presumed surface states on the semiconductor, similar to earlier ideas (cf. for example ref. ${ }^{27}$ ).

In the next step we applied the ligands to polycrystalline thin films of $\mathrm{Cu}(\mathrm{In}, \mathrm{Ga}) \mathrm{Se}_{2}$ of photovoltaic cell quality ${ }^{9,28}$. The changes in work function were much larger (cf. figure 2), while those in band bending, were much smaller (figure 3 ) than those observed for $\mathrm{CdTe}$ crystals. In this case we used a slightly different set of ligands, containing $\mathrm{CF}_{3}$ (a somewhat less electron-withdrawing group than $\mathrm{CN}$ ) and a methyl $\left(\mathrm{CH}_{3}\right)$ group instead of the methoxy one. This was done because of problems of protonation that were found to occur with the methoxy ligand. As shown in figures 1 and 2, the work function can be changed by over $1 \mathrm{~V}$, while the band bending changes by only tens of $\mathrm{mV}$.

CdS was next deposited on the ligand-treated $\mathrm{Cu}(\mathrm{In}, \mathrm{Ga}) \mathrm{Se}_{2}$. FTIR of the ligandtreated $\mathrm{Cu}(\mathrm{In}, \mathrm{Ga}) \mathrm{Se}_{2}$ did not allow us to establish the presence of the ligands after even a very thin $(<10 \mathrm{~nm}) \mathrm{CdS}$ film had been deposited because of adsorption of organic species from the CdS deposition process with similar IR bands to those of the ligands. In the final step, several tens of nm of Au were evaporated as $500 \mu \mathrm{m}$ diameter dots on the $\mathrm{CdS}$ covered surface. The dark I-V characteristics of the resulting device structures 


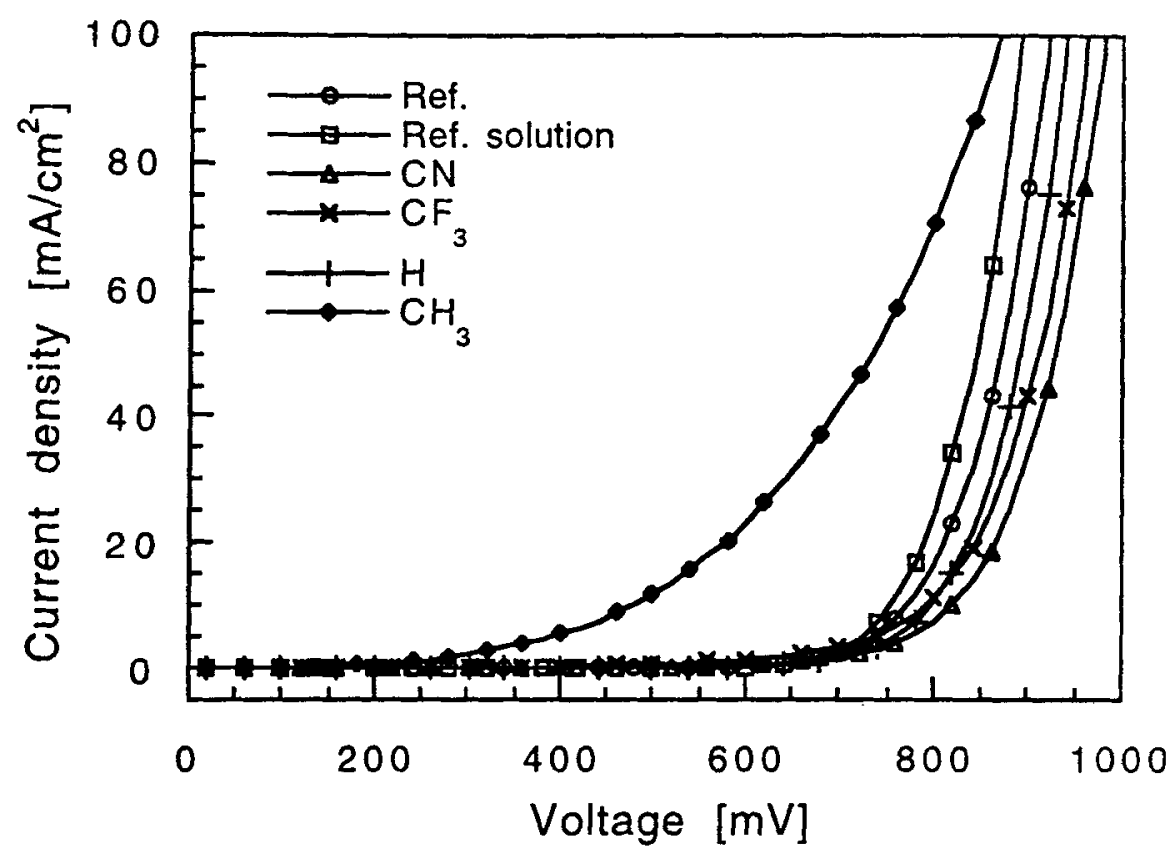

Figure 4. Dark current-voltage characteristics of $\mathrm{Au} / \mathrm{CdS} / \mathrm{CIGSe} / \mathrm{Mo}$ devices made without ("Ref.") and with ligand adsorption on the CIGSe, prior to CdS deposition. See legend to figure 2 for explanation of "Ref. solution".

were measured (cf. figure 4). From the figure it is clear that best blocking behaviour is seen with devices made with films to which the $\mathrm{CN}$-substituted ligand was bound. The order in which these characteristics deteriorate actually follows that given by the changes in dark work function.

Figure 5 shows light and dark I-V characteristics of the CIGSe + ligand/CdS/Au devices. These results, which could be reproduced with different batches of absorber films, represent the first clear-cut evidence that it is possible to use molecules at a hidden interface to influence charge transport through a solar cell. The reasons for this behaviour can be attributed to one or more of the following. Better band line-up; however this is not very likely as earlier we measured the band line-up of this type of cell and found no spike and a very small positive conduction band discontinuity ${ }^{29}$; Higher built-in voltage; (difference in measured open-circuit voltage between $\mathrm{CN}$ - and $\mathrm{OCH}_{3}$ treatments from 370 to $470 \mathrm{mV}$ ); this awaits the results from experiments that repeat the earlier ones on CdTe. If these can be taken as a guideline.then this explanation is also unlikely as the opposite effect was observed at the free surface; Defect passivation; this can lead to change in surface recombination velocity. In the case of single crystal $\mathrm{CdTe}$, time-dependent photoluminescence experiments with the adsorbed ligands showed this not to be the case. (Y Rosenwaks private comunication). Experiments to probe this directly on the thin films of CIGSe are planned.

After adsorbing the organic ligands onto the semiconductor absorber surface, clear effects are seen in the CPD measurements on free surfaces and, after CdS deposition, in 


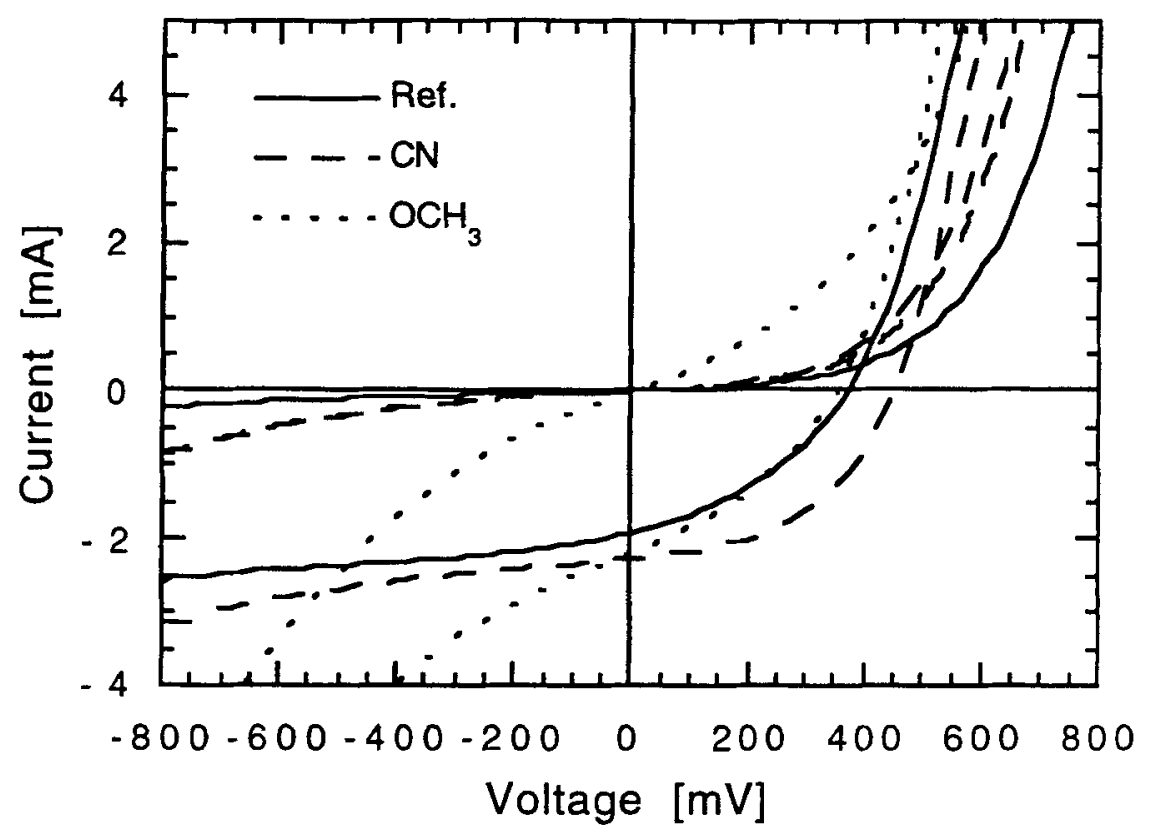

Figure 5. Dark and photocurrent-voltage characteristics of $\mathrm{Au} / \mathrm{CdS} / \mathrm{CIGSe} / \mathrm{Mo}$ devices made without ("Ref.") and with ligand adsorption on the CIGSe prior to CdS deposition. The several $\mathrm{mm}^{2}$ patch of Au blocks the ca. AM 1.5 intensity light partially.

the I-V characteristics of the cell structures. Although the role of the ligands in inducing these changes is not yet well understood, it is a topic of current investigations.

\section{Conclusions}

We have shown that molecular treatments can be used to affect charge transport properties of $\mathrm{Cu}(\mathrm{In}, \mathrm{Ga}) \mathrm{Se}_{2}$-based thin film polycrystalline photovoltaic devices. We stress that these effects are observed, nothwithstanding the fact that it is quite certain that the molecules do not form a continuous layer, separating the $\mathrm{CdS}$ window from the (In, $\mathrm{Ga}) \mathrm{Se}_{2}$ absorber. This means that in this case, in contrast to most other uses of molecules on semiconductors, internal short-circuiting is not a problem. This is so because the effect of the molecules is not so much to affect charge transport by having the charge carriers pass through them, but rather by influencing the energetics of the semiconductor interface which they have to cross. In this respect, there is thus a cardinal difference between the molecular effects observed here and those sought in many other cases ${ }^{30}$ where the electronic charge carriers need to pass through the molecules (be it through space or through bond). Thus this opens a new dimension of work on what has been often named molecular electronics but which can better be called molecule-based electronics. For the solar cells what is needed now is a larger variety of molecules, both in terms of binding groups and in terms of compatibility with window layer deposition and post-deposition cell treatment. Experiments along these lines are in progress in our laboratories. 


\section{Acknowledgments}

This work is supported by the Israel-German Energy Research program through the KFA Jülich \& the Israel Ministry of Science and the Arts, Jerusalem and by the MINERVA (Münich) foundation. We thank Dr Leeor Kronik (Tel Aviv Univ. and I. D. F.) for useful discussions. Eli Sone thanks the Karyn Kupcinet International Summer School at the Weizmann Institute for a fellowship.

\section{References}

1. a. cf. 13th NREL Photovoltaic Program Review, Ullal H S and Witt CE 1996 eds., AIP Conf. 353 (AIP, Woodbury)

b.Conf. Rec.25th Photovoltaic Specialists Conference, Washington, May 13-17, 1996 (IEEE, NY, NY), in press.

2. "Polycrystalline Semiconductors III, - Physics and Technology", H P Strun, J H Werner, B Fortin, O Bonnaud 1994 eds., (Scitech, Switzerland)

3. cf. special issue of Solar Cells, 198616

4. Shay J L, Wagner S and Kasper H M 1975 Appl. Phys. Lett. 27 p. 89

5. Kazmerski L L, Ayyagari M S, White F R and Sanborn G A 1976 J. Vac. Sci. Technol. 13 p. 139

6. Basol B M 1992 J. Vac. Sci. Technol. A10 p. 2006

7. Rockett A and Birkmire R W 1991 J. Appl. Phys. 70 p. R81

8. Rockett A, et al 1994 Thin Solid Films 237 p. 1

9. Hedström J, et al 1993 Proc. 23rd IEEE Photovoltaics Specialists Conf. Louisville, KY, p. 364; cf. also Stolt L et al in Proc. 13th Europ. PV Solar Energy Conf. (Nice, France 10/95); J. $\mathrm{R}$ Tuttle et al ibidem; $\mathrm{S} Z$ weigart et al, ibidem; Y. Ohtake et al in ref. 1b; T Wada in ref. $1 \mathrm{~b}$.

10. Braunger D et al. in ref. 1b; Braunger D et al 1996 Sol. En. Mater. Sol. Cells, 40 p. 97; T. Walter et al, 13th Eur. PV Solar En. Conf. and Exhibition (Nice, France, 1995), (in press).

11. Klenk R, Schock H W 1994 12th Eur. PV Solar En. Conf. and Exhibition, Amsterdam, April 11-15, p. 1588.

12. Saad M, Riazi H, Bucher E, Lux-Steiner M Ch, 1996 Appl. Phys. A62 p. 181

13. Schock H W, 1994 12th Eur. PV Solar En. Conf. and Exhibition, Amsterdam, April 11-15, p. 944.

14. Hariskos D, Ruckh M, Walter T, Schock H W 1994 1st WCPEC (IEEE, Hawaii), p. 91

15. Hariskos D, Herberholz R, Ruckh M, Rühle U, Schäffler R and Schock H W 1995 13th European Photovoltaic Solar Energy Conference and Exhibition (Nice, France), (in press).

16. Lincot D, Ortega-Borges R, Vedel J, Ruckh M, Kessler J, Velthaus K O, Hariskos D and Schock H W 1992 11th EC PV Solar Energy Conf. (Montreux)

17. Dagan D, Ciszek T, Cahen D 1992 Phys. Chem., 96 p. 11009

18. Cahen D, Noufi R 1989 Appl. Phys. Lett. 67 p. 558

19. Cahen D and Noufi R 1991 Solar Cells, 30 p. 53

20. Mirovsky Y, Cahen D, Hodes G, Tenne R and Giriat W 1981 Sol. En. Mats. 4 p. 169

21. Lokhande C D and Hodes G 1987 Solar Cells, 21215

22. Siripala W et al 1993 Appl. Phys. Lett. 62 p. 519

23. Moons E et al 1993 Jpn. J. Appl. Phys.32 Suppl. 32-3, p. 730

24. Bruening M et al 1994 J. Amer. Soc. 116 p. 2972

25. Bruening $M$ et al 1995 J. Phys. Chem. 998368

26. Bruening M 1996 Controlling Semiconductor and Metal Surfaces via Organic Ligand Adsorption. Ph. D. thesis, Feinberg Grad. School. Weizmann Institute of Science.

27. Kepler K D, Lisensky G C, Patel M, Sigworth L A and Ellis A 1995 J. Phys. Chem.

28. Zweigart $S$ et al 1995 in Proc. 13th Europ. PV Solar Energy Conf. (Nice, France 10)

29. Kronik L et al 1995 Appl. Phys. Lett., 671405

30. Petty M C, Bryce M R, Bloor D 1995 An introduction to molecular electronics" (Arnold, London) 